This is a post-peer-review, pre-copy edited version of an article published in Voluntary Sector Review. The definitive publisher-authenticated version Jacklin-Jarvis, C. (2015) 'Collaborating across sector boundaries: a story of tensions and dilemma', Voluntary Sector Review, 6 vol (3), pp.285-302 is available online at:

https://www.ingentaconnect.com/content/tpp/vsr/2015/00000006/00000003/art00003;jsessionid= 3wg66lr18vw96.x-ic-live-02

\section{Collaborating across sector boundaries: a story of tensions and dilemma}

\section{Introduction}

Collaboration theory provides an account of managing and leading in inter-organisational contexts in terms of the management of tensions. This literature focuses on the challenges and behaviour of those who lead collaborative entities ('partnership managers') (Vangen and Huxham, 2003) and of 'public managers' (O'Leary and Bingham, 2009a). However, it does not fully uncover the significance of inter-organisational context for collaboration actors managing these tensions. This paper explores the value of a tensions approach for understanding the experience of individuals who collaborate across the public/voluntary sector boundary on behalf of voluntary sector organisations (VSOs) ${ }^{1}$. It argues that sector context and the power dynamics of the cross-sector relationship are both key to understanding the tensions which individuals encounter. The paper contributes to collaboration theory by examining that theory through a lens of asymmetrical power relations, in which individuals endeavour to contribute to the shared purposes of the collaboration, whilst at the same time asserting the values, mission and independence of their organisation.

The paper draws on a three year qualitative study of individuals engaged in collaboration across the public/voluntary sector boundary in the context of children's services in England, to address the questions:

What are the tensions which voluntary sector (VS) actors encounter as they collaborate with public agencies in the children's services context; what are the implications of those tensions for practice; and how do they extend the tensions approach in collaboration theory?

Research participants characterised the experience of engaging in cross-sector collaboration on behalf of VSOs as frequently one of disempowerment. This was due, firstly, to public sector control of decision-making and resources, and, secondly, to the dynamic policy environment, which continually repositions the relationship between state and voluntary sector (Alcock and Kendall, 2011; Hogg and Baines, 2011; Lewis, 2005). Collaborative entities (partnerships, and joint projects) are frequently short-lived; their purposes and processes are ambiguous and overlap; and they are subject to changing political priorities and public sector reorganisation. As a result, the experience of collaborating is one of fragmentation and frustration. Conceptualising this experience in terms of experienced and inherent tensions gives insight into the compromises, trade-offs and dilemmas which VS actors face in cross-sector contexts, and the extent to which these are similar to or different from tensions encountered by other collaboration actors.

The paper identifies three inter-related tensions which VS participants encounter as they collaborate across sector boundaries in the children's services context, seeking to influence public sector 'partners' on behalf of their organisation, its mission, and the wider sector, whilst contributing to the 'joining-up' of services.

- The Agency/Dependency tension focuses on the individual's sense of their ability to make things happen, in a context where decision-making and resources are ultimately in public sector control. 
- The Values/Pragmatism tension focuses on commitment to values rooted in VS identity, but acceptance of a pragmatic approach to make things happen.

- The Distinctiveness/Incorporation tension focuses on maintaining a distinctive 'voice', whilst providing a 'joined-up' approach to complex social issues.

The paper argues that these experienced tensions derive from the inherent unity/diversity tension recognised in the literature (Ospina and Saz-Carranza, 2010; Saz-Carranza and Ospina, 2011), but that they also relate to the power dynamics between collaborating organisations, which in the children's services domain are played out through the endeavour to provide integrated services.

\section{Context}

The inter-organisational domain (Trist, 1983) in which services for children and families are delivered is framed by policy debates about the purpose and value of such services, and the role and responsibilities of public agencies and non-state actors. This section of the paper outlines the dynamic policy context of the empirical research, which took place over the period of the UK government change in 2010. Specifically, it focuses on the policy endeavour to 'join-up' services for children through cross-sector 'Children's Trust arrangements', including formal boards, commissioning arrangements, and related partnerships for service planning and coordination (Department for Children Schools and Families, 2008), and on the implications for VSOs focused on the needs of children and families. This is set against the wider context of the UK voluntary sector's increasing role in service delivery on behalf of the state, and consequent financial dependence (Clifford et al., 2010), which has impacted perceptions of the sector's independence and identity (Crouch, 2011; Lewis, 2005; Smerdon and Deakin, 2010), and raised concerns regarding power differentials within and across sectors (Milbourne, 2013).

The 1997-2010 Labour government's promotion of cross-sector collaboration to tackle seemingly intractable social issues led to multiple and overlapping partnership arrangements at the local level (Bailey, 2003). Within the children's services context, these included partnerships focused on safeguarding, early years' provision, youth services, child poverty, extended services, parenting, family intervention, and localities, with strategic development led by cross-sector Children's Trust Boards (Allnock et al., 2006; Bachmann et al., 2009; Dudau, 2009; Horwath and Morrison, 2007; Milbourne et al., 2003; Percy-Smith, 2005). These multiple partnerships represented an endeavour to achieve whole system change, moving beyond service co-ordination and towards integration (Horwath and Morrison, 2007). This journey towards integration implied increased joint decisionmaking and shared responsibility for resources, with a consequent reduction in the autonomy of collaborating agencies (ibid).

The boards, partnership meetings and working groups of Children's Trust arrangements provided a framework for determining local policy and priorities, and influencing the commissioning of services funded by local public agencies. Final responsibility for Trusts lay with local authority senior managers and councillors, with local sub-groups frequently led by local authority commissioners. Two issues arose for VSOs engaged with these arrangements. Firstly, with large funding streams allocated to children's services, and increased outsourcing of service delivery, VSOs found themselves competing for funding with 'partners' from within and beyond sector boundaries (Milbourne, 2009). Secondly, government policy from this period reasserted local authority responsibility for children's services, but provided little guidance on the engagement of VSOs in strategic planning and decision-making, rather than service delivery (Department for Children Schools and Families, 2007; Department for Education and Skills, 2003, 2004). This conveys a somewhat different picture of 'integration' to that described above, with VSOs contributing their 
resources to a public sector led agenda, whilst participating in stakeholder forums, in which they play an advisory or consultative role (Fung, 2006).

The 2010 change of government led to policy change in three significant areas for VSOs collaborating with public agencies to plan and deliver children's services. Firstly, government removed the requirement for cross-sector Children's Trust Boards (Department for Education, 2012). Secondly, this took place within a broader policy context which highlighted local determination (UK Parliament 2011), and replaced the policy discourse of 'partnership' (Lewis, 2005) with that of 'Big Society' (Alcock, 2010a; Bunyan, 2013). Thirdly, the policy of austerity reduced funding available for local commissioning. Given discretion to determine the form of Children's Trust arrangements, some local authorities retained cross-sector boards, some changed their form, and others dismantled them, together with the raft of associated collaborative arrangements, distancing VSOs still further from decision-making. While welcoming the profile which the 'Big Society' narrative brought, leaders from children's VSOs questioned its coherence, and potential for implementation in the context of public sector cuts (Evans, 2011), to which children's organisations were perceived to be particularly vulnerable (Davies and Evans, 2012).

This brief account of the policy context during the Labour and Coalition administrations highlights the formal authority of public agencies within the children's services domain, their control of critical financial resources, and of the policy discourse within which those resources are prioritised (Hardy and Phillips, 1998). The empirical research took place in a context in which the policy discourse, processes, and funding for cross-sector collaboration in children's services were in flux, leading to uncertainty regarding the future of such collaboration. While in one sense, this context can be seen as brought to the fore by the change of government, it relates to an ongoing debate about the respective roles of public agencies and VSOs to improve the wellbeing of and deliver services for children and families (Garrett, 2009), and to the wider debate about the relationship between VSOs and the state (Alcock, 2010b; Alcock, 2013; Hogg and Baines, 2011; Lowndes and Squire, 2012; Macmillan, 2011; Macmillan, 2013).

This research explores the experience of VSO leaders who worked collaboratively with public sector colleagues to 'make things happen' (Huxham and Vangen, 2000), influencing public sector actors, and consequently the agenda and direction of the collaboration, in this dynamic and uncertain context.

\section{Collaboration theory}

The literature of inter-organisational collaboration highlights its potential and its complexity. Collaboration combines resources and expertise to address complex social problems, which lie in inter-organisational domains (Trist 1983) - increasing the potential for creativity and innovation; introducing shared language and systems; and joining-up service provision (Crosby \& Bryson 2005, Gray 1985, Osborne 2008, Page 2003). The literature also acknowledges the difficulty, complexity, and ambiguity of collaboration - processes consume resources; participants become discouraged; and collaborative partnerships enter a state of 'collaborative inertia' (Huxham and Vangen, 2005). Differences in language, size, objectives, culture, systems, interdependencies, resources, identity, and expectations, are sources of potential conflict (Axelsson and Axelsson, 2009; Gazley and Brudney, 2007; Lundin, 2007; Vangen and Huxham, 2012; Vangen and Winchester, 2014), and threaten to pull partners apart (Connelly et al., 2008). To lead in collaborative contexts is therefore to encounter and manage tensions (Das and Teng, 2000; Huxham and Beech, 2003; Huxham and Vangen, 2005; O'Leary and Bingham, 2009b; Provan and Kenis, 2008; Saz-Carranza and Ospina, 2011; Vangen and Winchester, 2014; Vlaar et al., 2007). However, it is less clear whether these tensions 
are the same for all participants, or more specifically related to the organisation they represent and their role in relation to the collaboration.

Researchers use the term 'tensions' in at least three distinct ways. The first describes the individual's experience of engaging in collaboration (O'Leary and Bingham, 2009b; Williams, 2013). This draws attention to the difficult choices which individuals must make, the trade-offs and compromises. It highlights competing pressures, the dilemma of choosing between two (or more) apparently reasonable responses to the challenges of collaborating (Huxham and Beech, 2003). An example is the choice to focus on dealing with conflict in collaboration through bargaining and negotiation, rather than responding with confrontation (O'Leary and Bingham, 2009b). Too much confrontation risks alienating other participants; too little confrontation and there is a risk of absorption into the dominant perspective. The literature suggests that these experienced tensions are common in inter-organisational contexts, due to collaborators' competing interests and perspectives.

The second use of the term describes tensions as inherent in inter-organisational collaboration, due to its paradoxical nature (Huxham and Vangen, 2005; Lasker et al., 2001; Ospina and Saz-Carranza, 2010; Saz-Carranza and Ospina, 2011; Vangen and Huxham, 2012; Vangen and Winchester, 2014). A key expression of this is the unity/diversity tension which is fundamental to achieving collaborative advantage (Huxham and Vangen, 2005; Ospina and Saz-Carranza, 2010; Saz-Carranza and Ospina, 2011). While collaboration necessarily draws attention to that which collaborating organisations share, paradoxically, collaborative advantage is only achieved by drawing on each organisation's distinctive contribution (Huxham and Vangen, 2005). Differences between partners cannot and should not be elided - they are essential to achieving the synergy through which collaborative advantage is achieved (ibid). Instead, leaders should seek to manage tensions which inevitably arise from bringing together diverse partners (Saz-Carranza and Ospina, 2011). This emphasises a 'both and' rather than 'either or' approach to paradoxical aspects of collaboration:

'As leaders tried to make things happen, they were confronted with managing paradoxical realities.... In this work, they found the means to ensure that both sides of the paradox were honoured.' (Ospina and Saz-Carranza, 2010, p.414)

The emphasis on that which partners share, associated with alignment and integration (Crosby and Bryson, 2005), is allied to a simultaneous emphasis on the diversity and differentiation of collaborating organisations (Connelly et al., 2008; O'Leary and Bingham, 2009b; Ospina and SazCarranza, 2010).

The third use of the term is in the theoretical conceptualisation of management tensions as 'handles for reflective practice' (Huxham and Vangen, 2005). This approach explores alternative ways of managing the inevitable tensions in inter-organisational collaboration, by exposing the negative and positive aspects of each (Huxham and Beech, 2003; Vangen and Winchester, 2014). It is a way of presenting extremes of action as equally valid alternate 'good practice' responses to the tensions inherent in collaboration, and helping leaders to position themselves in relation to these extremes (Huxham and Beech, 2003; Huxham and Vangen, 2005), both of which are likely to be difficult if not impossible in practice. Theoretical conceptualisation provides tools to aid reflective practice, enabling the practitioner to manage the 'store of possibilities' (Huxham and Vangen, 2005, p.234).

An example (ibid p.217) relates to the difficult issue of managing aims. While common wisdom asserts that moving collaboration forward is dependent on agreement over aims, in practice, such agreement is difficult to find. Alternative advice suggests that participants act together on shared tasks, without first agreeing aims, but this can lead to later difficulties, when divergent 
organisational aims emerge. An intermediate position might be to seek enough agreement to make initial progress.

While these approaches to the topic of tensions operate at different levels, they each reinforce the point that there is no one best way to act in collaborative contexts. They draw attention to the difficult choices those engaged in collaboration must make, and the potentially negative as well as positive outcomes of those choices, even when following apparently good practice advice.

Researchers have surfaced the implications of a 'tensions' approach to collaboration for leadership practice (Connelly, 2007; Connelly et al., 2008; Huxham and Vangen, 2000; O'Leary et al., 2009; Vangen and Huxham, 2003). Individual actors leading collaborative entities adopt behaviours which address the tensions of collaboration, whilst moving that entity forwards. For example, studies of those tasked with leading collaborative networks identity the need for practice which both promotes unity and upholds diversity (Ospina and Saz-Carranza, 2010; Saz-Carranza and Ospina, 2011), surfacing differences, but agreeing to disagree, in order to retain member engagement. The dyadic concepts of 'collaborative thuggery' and 'the spirit of collaboration' (Vangen and Huxham, 2003) capture the apparently contradictory activities of partnership managers, which result from the attempt to address the inherent tensions of collaboration. Partnership managers are seen to engage in co-existing yet opposing styles of leadership - on the one hand facilitative leadership 'in the spirit of collaboration', and on the other hand a more directive approach 'towards collaborative thuggery' (Vangen and Huxham, 2003). Both of these are necessary to the nurture of collaboration. Similarly, a study of collaborating social change organisations identified the paradoxical need for practice which surfaces differences, whilst seeking to develop commonality (Ospina and Foldy, 2010), and the consequent trade-offs between facilitating the expression of different voices and ideas, and ensuring collaborators move forward together.

In identifying the tensions encountered by actors in collaboration, these studies adopt the collaborative entity (eg. partnership) as the unit of analysis, exploring leadership practice (activities, behaviours and meaning-making) which move the collaboration forward. The current paper adopts a different unit of analysis, focusing on VS participants acting to achieve their objectives, in collaborative contexts dominated by public policy and public sector resources. This VS participant perspective surfaces a distinct set of tensions which highlight the specific dilemmas, risks and tradeoffs of collaborative practice encountered those who represent their organisation and the wider sector through the inherent tensions of collaboration.

\section{Methodology}

The research adopted a qualitative methodology to explore the experience of VS participants in cross-sector collaboration in a swiftly moving context of policy and practice, working inductively to build theory from the data. The research drew on multiple data sources, and adopted multiple layers of analysis to uncover the experience of cross-sector collaboration. This was not, however, an attempt to aggregate data from different sources to find 'truth' or develop a 'whole picture' (Silverman, 2005). Instead, the aim was to develop 'thick description' (Geertz, 1973) surfacing, rather than reducing the complexity of practice in context.

Data collection included: observation of meetings; collation of meeting documents, including minutes, terms of reference and working papers of Children's Trust boards from three localities; documents from organisational websites, community information points, and from informants; key children's services policy documents from Labour and Coalition administrations; and semi-structured interviews with 21 individuals. Interviewee recruitment proceeded through a snowballing approach, 
beginning with the author's contacts from previous employment in a local authority children's department. These initial participants related to the local Children's Trust through their engagement in the wide range of partnership groups linked to the Trust, and through endeavours to deliver 'joined-up' services for children and families. They identified further participants engaged with Children's Trust arrangements to identify needs, plan and coordinate services in and beyond the immediate locality. As a result, participants clustered around two adjoining local authority areas, one an urban unitary authority, and the second a rural two tier county authority, with several participants working across locality boundaries.

Three participants worked for infrastructure organisations with a specific remit to facilitate crosssector engagement. Others collaborated with public agencies on behalf of organisations providing services to support children and families at the local level, both under contract to public agencies, and funded by external resources. Although several of these organisations were federated nationally, the focus here is on their local expression, where they operate as small to medium sized organisations, described by Rochester as associational/bureaucratic hybrids (Rochester 2013 p.236). While the focus of the interviews was on participants' experience of collaborating with public agencies from a position of leadership in VSOs, ten of the 21 interviewees also had experience of working in public agencies.

Interview texts were analysed thematically, working inductively with the data to identify, analyse, and report patterns (Braun and Clarke, 2006, p.79). Codes were generated from the data in response to the research question and stored using the qualitative data software, NVivo. A second stage of analysis focused on interviewees' language, specifically on use of metaphor, as a way of accessing meaning-making (Cameron and Maslen, 2010; Coffey and Atkinson, 1996; Lakoff and Turner, 1989). Metaphor provided an alternative route into the interview texts, revealing something about the individual, their understanding of the world, and of themselves (Lakoff and Turner, 1989). More specifically, focusing on interviewees' discourse through metaphor, provided greater insight into individual experience of collaboration. This stage of analysis followed the stages outlined by Cameron and Maslen (2010)- identify the metaphors; consider the context; find patterns in use; draw interferences from use.

In addition, observation notes were reviewed, reflective notes added, and narrative vignettes developed as a way of making sense of observed practice. A separate qualitative content analysis (Bryman, 2008) of policy documents from children's services was also stored in NVivo. All references to collaboration and the voluntary sector in these documents were coded using both electronic searching and repeated re-reading to identify synonyms and antonyms. Initial codes were then grouped thematically in NVivo in order to identity key narratives of public/voluntary sector collaboration, and to identify similarities and differences across policy documents. The processes of data analysis were therefore multiple and iterative, repeatedly interacting with the data to produce rich analysis (Coffey and Atkinson, 1996, pp.15-16), and a 'thick description' (Geertz, 1973; Ponterotto, 2006) of collaborative practice in the children's services context.

\section{Findings}

This section of the paper summarises the findings of the research, illustrating those findings with brief vignettes and excerpts from interview texts, including examples of metaphors in use. The findings, and the discussion which follows, highlight three tensions experienced by VS actors, and the difficult decisions, trade-offs, and compromises which resulted from these experiences. Running through these findings is a theme of collaborating in a context of dependency and power asymmetry. 


\section{Agency/Dependency}

The first tension which participants experienced related to their agency, in terms of ability to make things happen within a collaborative context where decision-making and control of public resources ultimately reside with public sector agencies. This is particularly evident when changes are made to local structures and processes for collaboration. One VS representative to a Children's Trust Board described recent changes as 'all graciously done', but also 'done surreptitiously', revealing the 'seniority' of public agencies. A second participant described the experience of collaborating with the local authority over time as a roller coaster ride, in which public agencies determine, and redetermine, the direction of travel:

'You think you're making progress, and then it goes like that again, and then there's a bit of an upturn, and then it goes like that again.' (Moves her arms up and down to denote 'roller coaster' ride.) (Fiona)

An experienced sector representative suggested that it is rare to make significant impact through the formal meetings of cross-sector partnership:

'... you can raise questions, you can raise concerns, but I don't feel that my being at that particular group or level has made a lot of difference, really. On the odd occasion, you might find that there's something where you can challenge or get some information taken on board, but that's pretty rare.' (Colin)

Participants attributed these experiences to a context which dominated by public sector policy and resources. Only one participant claimed that his organisation had no financial relationship at all with public agencies. Others were acutely aware of their organisation's dependence on funding from the local authorities who also led local Children's Trust arrangements:

'I always think about partnership work as being on an equal footing, and actually the reality is that there isn't, because they give us - we're reliant on them, $70 \%$ of our funding comes from them. So, it's not partnership in the true sense.' (Ellie)

Yet, in spite of these experiences of disempowerment, research participants continued to engage in multiple cross-sector arrangements, and to believe that they make things happen through this engagement:

'I'm not a cog, a small cog in a big machine, I'm actually making things happen.' (Ian)

This tension between the experience of disempowerment on the one hand, and identification as agent of change on the other, plays out in ways in which individuals find ways to 'work around' public sector dominated collaboration processes. Influence is frequently enacted backstage, through contacts between individuals, rather than through formal processes:

'Often, it's the conversations after the meeting that will lead to something happening more than the things that happen during the meetings, you know. And if you're not there, meeting people who have got the influence, and, you know, then you're going to lose out.' (Colin)

Collaborating in cross-sector contexts where actors are committed to making a difference, yet at the same time perceive that control is in the hands of 'partner' public agencies leads to continual 
frustrations for individuals. It raises difficult questions about when it is acceptable to attempt to bypass public sector dominated processes, and instead rely on contacts with key people to exert influence. Paradoxically, this in turn reinforces the sense that individuals matter, and that they can make things happen on behalf of their organization and its mission.

\section{Values/Pragmatism}

The second tension which research participants experienced focused on values. Participating in cross-sector collaboration initiated by public policy and led by public agencies led them to question when to take a stand on values associated with the cause of their organisation, the community it serves, and the wider sector; and when to act pragmatically in order to sustain the collaboration. A values based approach resonates with the narrative of an independent, mission-driven sector; a more pragmatic approach focuses on what is practicable and achievable, potentially compromising values, in order to work within the constraints of public sector policy and processes. In the words of one participant,

'You have to make pragmatic judgements, and be politically realistic.' (Eric)

In one example, a Chief Exec explains how her organisation objects in principle to changes made by the local authority, but chose not to voice this objection within a meeting of the local children's partnership in order not to jeopardise collaborative relationships. Instead, the organisation set up a separate opportunity for local parents to meet with a key local authority manager. This enabled them to state their concern through service users, reinforcing their values stand, whilst accepting that the local authority is unlikely to change its position, and avoiding overt disruption to partnership processes. In this example participants found a way to express the values commitment of their organisation, whilst living with local authority policies which challenged those values.

In a second example, an experienced sector representative chose to challenge the representatives of public agencies in a voluntary sector forum in which the latter were invited guests. As leader of a VSO focused on the needs of an excluded group of young people, Thomas interrupted the collaborative flow of the meeting to warn public sector representatives that failure to re-visit a recent funding decision, which again excluded this group, would lead to a legal challenge. This challenge was not repeated in the more public forum of the Children's Trust Board, and any risks of this strategy for future cross-sector collaboration were mitigated by informal backstage agreements made with other VSOs also committed to the value of inclusion. At the following forum meeting, Thomas announced that the local authority had indeed allocated funding to work with these excluded young people.

Again, these examples of encountering the tensions of collaboration lead to difficult judgements and dilemmas for individual actors as they determine when and how to challenge public sector agencies, and when compromises are acceptable or not - both for their own organisation and for the continuing collaboration.

\section{Distinctiveness/Incorporation}

The third tension participants encountered related to the desire to maintain distinctiveness, whilst contributing to a 'joined-up' approach to complex social problems. On the one hand, an overemphasis on distinctiveness means that collaboration fails to offer a co-ordinated approach to social problems. On the other, 'joined-up' service delivery potentially masks the distinctive contribution of different organisations and sectors, with a risk that VSOs are perceived by stakeholders as effectively incorporated into the public sector. For the research participants, the challenge of managing the 
tension between distinctiveness and incorporation was frequently compounded by their organisation's dependency on public sector resources.

The desire to offer a distinctive understanding and contribution to addressing complex social problems, is a key motivation to collaborate:

'I think we come with a different perspective, a different understanding and I believe you know, often more in touch with services users, so I think we can bring a different perspective, and influence the way services are developed and commissioned.' (Colin)

However, processes designed to deliver integration tend to blur differences between organisations and sectors:

'...the public sector certainly just wants to commission, as it were, and ideally, very often, the legal procurement people want to have single contracts, and that militates against a vibrant, diverse voluntary sector.' (Ian)

The implications of this 'joined-up-yet-distinctive' approach for VS collaborators is illustrated by a participant whose work places her in a collaborative context on a daily basis. She describes herself as working 'undercover':

I'm here physically every day, these are the people that I see, and I'm now being aware I suppose just that it's a kind of undercover cop, you get the gang.' (Charlotte)

Charlotte chooses to appear no different from those around her, believing that she can best promote her organisation's purposes, and maintain the collaborative relationship, from this position. The metaphor of the 'undercover cop' conveys a sense of hidden identity, but also of the resulting dilemmas as to when and how she should reveal herself as representative of a distinctive and independent organisation.

This reveals something of the continual pressure which the tensions of cross-sector collaboration place on individuals who represent their organisation and the wider sector. One participant describes the experience of collaborating across sector boundaries as 'straddling different realities' (Eric), whilst another describes his role as sector representative as that of a Janus figure, looking simultaneously towards the local authority on the one hand and to the VSOs he represents on the other. Such metaphors convey something of the implications for individuals, the challenges and discomfort, as they engage with the tensions of collaboration in a context of power asymmetry. In practice terms, the experienced tensions of cross-sector collaboration lead to repeated dilemmas, compromises, and trade-offs for VS actors.

The discussion which follows explores how the tensions identified in this research relate to those identified in extant collaboration theory, and in turn highlights the significance of interorganisational and sectoral context for a tensions approach to collaboration theory. It points towards the practice implications for VSO actors of a tensions approach to collaboration.

\section{Discussion}

This paper has introduced three inter-related tensions experienced by VS participants, drawing on the example of cross-sector collaboration in children's services. The discussion which follows relates these experienced tensions to those described in the literature. It extends current models of 
tensions in collaboration, to argue that experienced tensions, and the management of tensions by individual actors relate to inter-organisational context. For children's services, a key part of that context is the cross-sector relationship as it is framed by government policy and enacted in partnership arrangements in which agenda-setting, decision-making and resource allocation is framed by policy, and led by local public agencies. This asymmetrical relationship between public and voluntary sectors impacts on VS actors' experience of the tensions of collaboration and their responses to those tensions. The discussion closes by offering a 'handle for reflective practice' (Huxham and Vangen, 2005) which conceptualises this in terms of a management tension focused on power.

The experienced tensions - between agency and dependency, values and pragmatism, and distinctiveness and incorporation - which are described here relate to those previously identified in the collaboration literature. Specifically, these are similar to accounts of tensions between autonomy and interdependence (O'Leary and Bingham, 2009b), ideology and pragmatism (Vangen and Huxham, 2003), and integration and differentiation (Ospina and Foldy, 2010; Saz-Carranza and Ospina, 2011) encountered by collaboration actors. The literature relates these to an inherent tension between unity on the one hand and diversity on the other (Ospina and Saz-Carranza, 2010; Saz-Carranza and Ospina, 2011), highlighting the need for both integration and differentiation to move collaboration forward. In this study, VS participants frequently found it difficult to express difference through the assertion of a distinctive values-based voice. However, tensions theory affirms that the expression of difference is essential not only for participant organisations, but also for the collaboration. Indeed, paradoxically, collaborative advantage (when organisations achieve more together than they could alone) depends on the distinctive contribution of each participating organisation being brought into the whole, as synergy is drawn from difference (Huxham and Vangen, 2005). On the other hand, too much emphasis on difference means that there is insufficient commonality on which to build a collaborative relationship, or on which to offer 'joined-up' approaches to complex social problems.

For those who lead and manage collaborations, the focus is on ensuring that the collaboration continues and achieves its purposes, and on managing the tensions and associated compromises, trade-offs and dilemmas in relation to this over-riding purpose. Partnership managers face dilemmas related to who they include, whether to surface participants' aims, and how to encourage identification with the collaboration, rather than simply with participants' organisations (Vangen and Huxham, 2003). As a consequence, they may resort to behaviours which appear far from collaborative, including manipulation and 'collaborative thuggery' (Vangen and Huxham, 2003). In terms of the ambition to 'integrate' children's services, the focus of public agencies leading this process is to draw together different service providers, whilst ensuring those differences do not jeopardise the integrated approach. The consequence of this is seen in VS participants' frustration at being invited to contribute to 'joining-up' services, while their distinctive voice was all too frequently unheard.

From the perspective of collaboration participants (rather than those who manage collaborations), the survival and achievement of the collaboration itself is secondary to the achievement of the purposes of the organisation or sector they represent. This gives them a somewhat different approach to the tensions of collaboration. In the context of the endeavour to integrate children's services, tensions experienced by VS participants led to dilemmas related to when they should pragmatically accept public sector control; when to express distinctiveness or take a values stand, and when remain silent; and when and how to intervene into dominant policy discourses to influence the public sector led agenda. 
In other words, the experienced tensions of cross-sector collaboration and individuals' management of those tensions, relate to the inter-organisational context. More specifically, they relate here to a context in which there is asymmetry between collaborating actors from different sectors, in terms of agenda-setting, decision-making and financial resources. This asymmetry is reinforced by government policy alongside, and in apparent contradiction to, policy narratives which advocate partnership and service integration. The context of Children's Trust arrangements is therefore one in which public agencies retain formal authority, control critical financial resources, and frame the discourse through policy (Hardy and Phillips, 1998). The empirical data point to the impact of this asymmetry on VS actors, determining when and how to make a values-based stand, or reinforce a distinctive approach. Challenging and disrupting the dominant discourse is inevitably risky in terms of public agencies' authority and their control of decision-making and resources, but also in terms of the overriding ambition to achieve services which are integrated for service users.

As a result, like partnership managers (Vangen and Huxham, 2003), the VS actors in this study engage in behaviours which at times appear contradictory - on the one hand building collaborative relationships across the sector boundary through engagement in public sector led processes with little evidence of conflict, whilst, on the other, disrupting the processes of collaboration through backstage negotiations or public challenges. Informal backstage negotiations provide an opportunity to influence the agenda for future collaboration, whilst avoiding risks associated with public challenges to formal authority. Such negotiations maintain an appearance of integration, but may be seen as collusive. In contrast, interventions made in the public arenas of partnership meetings challenge dominant policy discourses in an endeavour to influence the direction of the collaboration, surfacing a distinctive perspective. However, actors making such interventions run the risk that their challenges result in exclusion from the resources controlled by public agencies, as they are no longer perceived as committed to integration. Apparently contradictory tactics of 'collaborative disruption' reflect Hardy and Phillips' (2005) advice to organisations with limited access to formal authority and resources to employ discursive strategies of both collaboration and conflict to contribute to the framing of the complex social problems which are the focus of interorganisational collaboration. This has some similarity to Ospina and Saz-Carranza's (2010) recognition that both dialogue and confrontation are necessary tactics for organisations collaborating to influence a powerful 'institutional target'. However, in the context of public sector led collaboration the institutional target is also the most powerful partner within the collaboration.

Collaborating within these power dynamics can be conceptualised as a 'management tension' (Huxham and Beech, 2003) to aid reflective practice, presenting VS actors with alternative good practice advice. On the one hand, advice to collaborators suggests that equal power facilitates collaboration (Gray and Hay, 1986), but this is frequently unachievable in practice, as the Children's Trust example illustrates. Indeed, behaviour which challenges the power imbalance may itself threaten the objective of integration. Alternative advice might focus on the potential for partners to act together on shared social concerns without addressing power asymmetries. Paradoxically, this may reinforce power asymmetry, giving the appearance of integration, but masking difference, as partners with less access to agenda-setting, decision-making and financial resources, become increasingly subject to the priorities of more powerful partners. An intermediate response to this 'power tension' was seen in the actions of research participants who adopted strategies which challenged dominant public sector discourses, whilst at the same time working collaboratively within a relationship of resource dependency in pursuit of public sector-led integration. Managing the 'power tension' implies adopting strategies which both accept and seek to work within power asymmetries and at the same time challenge them. The question for practitioners of collaboration is whether, how far, and in what circumstances, such compromises are acceptable. 


\section{Conclusions: collaborating within tensions}

This research applies the lens of tensions theory to a study of public/voluntary sector collaboration in the children's services context. The empirical data highlights tensions experienced by VS actors focused on agency/dependency, values/pragmatism, and distinctiveness/incorporation. These experienced tensions and the responses of individuals are seen to relate to the cross-sector context, and more specifically to power asymmetry between public and voluntary sectors, in which the former control access to resources, agenda-setting and decision-making. This is conceptualised as a management tension focused on power dynamics in collaborative contexts, within which participants are seen to engage in both collaborative and disruptive behaviours.

At no point in the study did participants suggest they had engaged in a frank discussion about power dynamics with public sector partners. Instead, VS participants described disengagement, informal backstage tactics, hiding distinctiveness, and occasional public challenges, with each of these responses carrying its own risks to continuing collaboration to achieve integrated children's services. Paradoxically, such behaviours sometimes enabled them to exert influence on public sector partners, leading to an increased role in the public sector-led integration of services, albeit with the risk that their distinctive contribution is again obscured.

This research draws on a small study of cross-sector collaboration based in one area of social welfare - children's services. It adopts an inductive and 'modest' approach to theory building (O'Reilly, 2009), which offers emergent concepts which may be generalisable to other contexts through a process of 'logical inference' (Clyde Mitchell, 1983). Specifically, conceptualizing power dynamics in terms of management of tensions may provide a way of exploring the strategies of actors in collaborative contexts where formal authority, critical resources, and discursive legitimacy (Hardy and Phillips, 1998) is by no means equally shared between collaborating organisations. More broadly, the study highlights the significance of context for the ways in which the inevitable tensions of collaboration are experienced by and managed by individual actors. Further research is needed to explore the significance of inter-organisational context, and more specifically of power dynamics, for the tensions approach in collaboration theory.

In the meantime, in children's services, a context where cross-sector collaboration is viewed as an almost inevitable response to resource scarcity, it is important to continue to surface the tensions of collaboration, and their implications for participants from different sectors. This may enable policymakers and practitioners alike to develop realistic expectations for such collaboration, which acknowledge the Janus-like experience of navigating sector boundaries.

\section{Notes}

${ }^{1}$ This paper uses the terms 'voluntary sector' and 'voluntary sector organisations', rather than civil or third sector, to indicate the focus of the research on organisations which take the form of registered charities, managed by volunteer trustees, rather than social enterprises or informal community associations.

\section{References}

Alcock, P, 2010a, Building the Big Society: a new policy environment for the third sector in England, Voluntary Sector Review, 1, 3,379-389

Alcock, P, 2010b, A strategic unity: defining the third sector in the UK, Voluntary Sector Review, 1, 1, $5-24$ 
Alcock, P, 2013, Challenging times: what is the future for the third sector?, Birmingham: Third Sector Research Centre

Alcock, P, Kendall, J, 2011, Constituting the third sector: processes of decontestation and contention under the UK Labour governments in England, Voluntas: International Journal of Voluntary and Nonprofit Organizations, 22, 3, 450-469

Allnock, D, Akhurst, S, Tunstill, J, 2006, Constructing and sustaining Sure Start Local Programme partnerships: lessons for future inter-agency collaborations, Journal of Children's Services, 1 , 3, 29-39

Axelsson, SB, Axelsson, R, 2009, From territoriality to altruism in interprofessional collaboration and leadership, Journal of Interprofessional Care, 23, 4, 320-330

Bachmann, MO, O'Brien, M, Husbands, C, Shreeve, A, Jones, N, Watson, J, Reading, R, Thoburn, J, Mugford, M, 2009, Integrating children's services in England: national evaluation of children's trusts, Child Care, Health \& Development, 35, 2, 257-265

Bailey, N, 2003, Local Strategic Partnerships in England: the continuing search for collaborative advantage, leadership and strategy in urban governance, Planning Theory and Practice, 4, 4, 443-457

Braun, V, Clarke, V, 2006, Using thematic anlaysis in psychology, Qualitative Research in Psychology, $3,2,77-101$

Bryman, A, 2008, Social research methods, Oxford: Oxford University Press

Bunyan, P, 2013, Partnership, the Big Society and community organizing: between romanticizing, problematizing and politicizing community, Community Development Journal, 46, 119-133

Cameron, L, Maslen, R, (eds), 2010, Metaphor analysis: research practice in applied linguistics, social sciences and the humanities, London: Equinox

Clifford, D, Fajme, FG, Mohan, J, 2010, How dependent is the third sector on public funding? Evidence from the National Survey of Third Sector Organisations, London: Third Sector Research Centre

Clyde Mitchell, J, 1983, Case and situation analysis, Sociological Review, 31, 2, 187-211

Coffey, A, Atkinson, P, 1996, Making sense of qualitative data: complementary research strategies, London: Sage

Connelly, DR, 2007, Leadership in the collaborative interorganizational domain, International Journal of Public Administration, 30, 11, 1231-1262

Connelly, DR, Zhang, J, Faerman, S, 2008, The paradoxical nature of collaboration, in R. O'Leary and L.B. Bingham (eds) Big ideas in collaborative public management, New York: M.E. Sharpe

Crosby, BC, Bryson, JM, 2005, Leadership for the common good: tackling public problems in a sharedpower world, San-Francisco: Josey-Bass

Crouch, G, 2011, A new age of interdependence: managing relationships between the voluntary sector and government, Voluntary Sector Review, 2, 2, 247-256

Das, TK \& Teng, BS, 2000, Instabilities of strategic alliances: an internal tensions perspective, Organization Science, 11, 1, 77-101

Davies, N, Evans, K, 2012, Perfect storms: an analysis of the operating conditions for the children, young people and families voluntary sector, London: Children England

Department for Children Schools and Families, 2007, The children's plan: building a brighter future, London: DCSF

Department for Children Schools and Families, 2008, Children's Trusts: statutory guidance on interagency cooperation to improve well-being of children, young people and their families, London: DCSF

Department for Education, 2012, A new approach for Children's Trust Boards, www.education.gov.uk/childrenandyoungpeople/healthandwellbeing/a00202982/anewappr oachfor-childrenstrustboards

Department for Education and Skills, 2003, Every child matters, London: DfES

Department for Education and Skills, 2004, Every child matters: change for children, London: DfES 
Dudau, A, 2009, Leadership in public sector partnerships: a case study of Local Safeguarding Boards, Public Policy and Administration, 24, 399-415

Evans, K, 2011, 'Big Society' in the UK: a policy review, Children and Society, 25, 2, 164-171

Fung, A, 2006, Varieties of participation in complex governance, Public Administration Review, Special Issue, 66-75

Garrett, PM, 2009, 'Transforming' children's services? Social work, neoliberalism and the 'modern' world, Maidenhead: Open University Press

Gazley, B, Brudney, J, 2007, The purpose (and perils) of government-nonprofit partnership, Nonprofit and Voluntary Sector Quarterly, 36, 3, 389-416

Geertz, C, 1973, The interpretation of cultures: selected essays, New York: Basic Books

Gray, B, Hay, TM, 1986, Political limits to interorganizational consensus and change, Journal of Applied Behavioral Science, 22, 2, 95-112

Hardy, C, Phillips, N, 1998, Strategies of engagement: lessons from the critical examination of collaboration and conflict in an interorganizational domain, Organization Science, 9, 2, 217230

Hogg, E, Baines, S, 2011, Changing responsibilities and roles of the voluntary and community sector in the welfare mix: a review, Social Policy \& Society, 10, 3, 341-352

Horwath, J, Morrison, T, 2007, Collaboration, integration and change in children's services: critical issues and key ingredients, Child Abuse and Neglect, 31, 1, 55-69

Huxham, C, Beech, N, 2003, Contrary prescriptions: recognizing good practice tensions in management, Organization Studies, 24, 1, 69-93

Huxham, C, Vangen, S, 2000, Leadership in the shaping and implementation of collaboration agendas: how things happen in a (not quite) joined-up world, Academy of Management Journal, 43, 6, 1159-75

Huxham, C, Vangen, S, 2005, Managing to collaborate: the theory and practice of collaborative advantage, London: Routledge

Lakoff, G, Turner, M, 1989, More than cool reason: a field guide to poetic metaphor, Chicago: University of Chicago Press

Lasker, RD, Weiss, ES, Miller, R, 2001, Partnership synergy: a practical framework for studying and strengthening the collaborative advantage, Milbank Quarterly, 79, 2, 179-205

Lewis, J, 2005, New Labour's approach to the voluntary sector: independence and the meaning of partnership, Social Policy and Society, 4, 2, 121-5

Lowndes, V, Squire, S, 2012, Cuts, collaboration and creativity, Public Money \& Management, 32, 6, 401-408

Lundin, M, 2007, Explaining cooperation: how resource interdependence, goal congruence, and trust affect joint actions in policy implementation, Journal of Public Administration Research and Theory, 17, 4, 651-672

Macmillan, R, 2011 'Supporting' the voluntary sector in an age of austerity: the UK coalition government's consultation on improving support for frontline civil society organisations in England, Voluntary Sector Review, 2, 1, 115-124

Macmillan, R, 2013, 'Distinction' in the third sector, Voluntary Sector Review, 4, 1, 39-54

Milbourne, L, 2009, Remodelling the third sector: advancing collaboration or competition in community-based initiatives?, Journal of Social Policy, 38, 2, 277-297

Milbourne, L, 2013, Voluntary sector in transition: hard times or new opportunities:, Bristol, Policy Press

Milbourne, L, Macrae, S, Maguire, M, 2003, Collaborative solutions or new policy problems: exploring multi-agency partnerships in education and health work, Journal of Education Policy, 18, 1, 19-35

O'Leary, R, Bingham, LB (eds), 2009a, The collaborative public manager: new ideas for the twentyfirst century, Washington, D.C.: Georgetown University Press 
O'Leary, R. \& Bingham, LB, 2009b, Surprising findings, paradoxes, and thoughts on the future of collaborative public management research, in R. O'Leary and L.B. Bingham (eds) The collaborative public manager, Washington, D.C.: Georgetown University Press.

O'Leary, R, Gazley, B, McGuire, M, Bingham, LB, 2009, Public managers in collaboration, in R. O'Leary and L.B. Bingham (eds) The collaborative public manager, Washington, D.C.: Georgetown University Press

O'Reilly, K, 2009, Key concepts in ethnography, Los Angeles: Sage

Ospina, S, Foldy, E, 2010, Building bridges from the margins: the work of leadership in social change organizations, Leadership Quarterly, 21, 2, 292-307

Ospina, SM, Saz-Carranza, A, 2010, Paradox and collaboration in network management, Administration and Society, 42, 4, 404-440

Percy-Smith, J, 2005, What works in strategic partnerships for children?, Ilford: Barnardo's

Ponterotto, JG, 2006, Brief note on the origins, evolution and meaning of the qualitative research concept "thick description", The Qualitative Report, 11, 3, 538-549

Provan, KG, Kenis, P, 2008, Modes of network governance: structure, management, and effectiveness, Journal of Public Administration Research and Theory, 18, 2, 229-252

Saz-Carranza, A, Ospina, SM, 2011, The behavioral dimension of governing interorganizational goaldirected networks - managing the unity-diversity tension, Journal of Public Administration Research and Theory, 21, 2, 327-365

Silverman, D, 2005, Doing qualitative research: a practical handbook, London: Sage

Smerdon, M, Deakin, N, 2010, Independence in principle and practice: relationships between the state and voluntary action, Voluntary Sector Review, 1, 3, 361-370

Trist, E, 1983, Referent organizations and the development of inter-organizational domains, Human Relations, 36, 3, 269-284

UK Parliament, 2011, Localism Act, London:TSO

Vangen, S, Huxham, C, 2003, Enacting leadership for collaborative advantage: dilemmas of ideology and pragmatism in the activities of partnership managers, British Journal of Management, 14, S61-S76

Vangen, S, Huxham, C, 2012, The tangled web: unraveling the principle of common goals in collaborations, Journal of Public Administration Research \& Theory, 22, 4, 731-760

Vangen, S, Winchester, N, 2014, Managing cultural diversity in collaborations: a focus on management tensions, Public Management Review, 16, 5, 686-707

Vlaar, PWL, Bosch, F, \& Volberda, HW, 2007, Towards a dialectic perspective on formalization in interorganizational relationships: how alliance managers capitalize on the duality inherent in contracts, rules and procedures, Organization Studies, 28, 4, 437-66

Williams, P, 2013, We are all boundary spanners now?, International Journal of Public Sector Management, 26, 1, 17-32 